\title{
Food insecurity of rural households in Boset district of Ethiopia: a suite of indicators analysis
}

\author{
Getachew Teferi Moroda* ${ }^{*}$, Degefa Tolossa and Negussie Semie
}

\begin{abstract}
Background: Despite several efforts made so far to improve the overall food insecurity situation, the challenge is still a major problem in Ethiopia since a long time ago. Hence, the purpose of this study is to examine the food insecurity situation and identify the determinants among the rural households of Boset district. To this end, 397 household heads were selected through systematic sampling technique from six sample kebeles. In addition, focus group discussions, key informant interviews, and personal observations were also used to supplement the survey data. Then, the food insecurity status of households was measured with a suite of indicators.

Results: The results revealed that $26.5 \%, 21.7 \%$, and $41.3 \%$ of respondents were highly food insecure through Months of Adequate Household Food Provisioning, Household Food Insecurity Access Scale, and Household Dietary Diversity Score, respectively. On top of these, $56.9 \%, 46.1 \%$, and $64.0 \%$ of the respondents did not have access to water supply, not owned latrine, and dispose waste in an unsafe way, respectively. Furthermore, results from the inferential statistics showed that educational status, farmland size, total annual income, distance from health facilities, and the availability of supporting organizations were positively associated with household food security situation, while access to irrigable land, frequent drought, distance to input/output markets, and distance to road transport were negatively associated.

Conclusion: From the study findings it can be observed that all the dimensions of food (in)security should be focused for effective intervention. More specifically, those determinants with both positive and negative associations with food security may deserve the attention of the local authorities. Similarly, there is a need for a reorientation of an approach which is beyond a quick and simple fix. Besides, an integration of efforts between different sectors at both local and national levels is sought to bring a lasting solution to food insecurity.
\end{abstract}

Keywords: Food insecurity, Determinants, Suite of indicators, Boset, Rural Ethiopia

\section{Background}

The issue of where our next meal comes from has bedeviled humankind for much of our existence [1]; thus, food insecurity is a daily reality for hundreds of millions of people around the world [2]. In our today's time, one can observe our world's population living in a situation where there are serious strains. To this end, it was illustrated that "a threefold challenge now faces the world: match

*Correspondence: kennakogt@gmail.com Center for Rural Development, College of Development Studies, Addis Ababa University, Addis Ababa, Ethiopia the rapidly changing demand for food from a larger and more affluent population to its supply; do so in ways that are environmentally and socially sustainable; and ensure that the world's poorest people are no longer hungry" [3]. Furthermore, it was predicted that "it seems incontrovertible that we are facing a global paradox, such that by 2030, we will have to produce more food with less water to feed approximately another billion people" [4].

A closer look at the Ethiopian context depicts that the food insecurity problem is an issue which deserves special attention to be tackled. Different scholars have depicted that food insecurity has been a daunting 
challenge to Ethiopia [5-8]. In recent years, commercial food import and food aid have been accounting for a significant proportion of the total food supply in the country [8]. Due to such high dependence on food import, Ethiopia was identified as vulnerable to uncertainties of food import from the international market [9]. Moreover, it was confirmed that, despite the attempts made to improve the food security situation, the actual number of people exposed to food shortages in Ethiopia has remained significantly high [10].

Oromia Bureau of Agriculture [11] indicated that the food insecurity situation in Boset district was so precarious. The bureau revealed that due to the fact that Boset district is prone to frequent drought, it was included in the Productive Safety Net Program (PSNP). A district could be included in the PSNP when confirmed by experts that there prevails chronic food insecurity situation. In 2014/2015 there were 58,131 households who were beneficiaries from the PSNP.

Based on the fact that food insecurity is a real challenge for the life and livelihood of Ethiopia, and the study area in particular, it can be justified for a further study so that a solution could be sought. It was mentioned that food security matters immensely, because the consequences of food insecurity can affect almost every facet of society [12]. In addition, a document produced by International Food Policy Research Institute (IFPRI) [13] has stressed that food insecurity situation is a human tragedy on a vast scale, made even more heartbreaking because it is avoidable. Schanbacher [14], on the other hand, mentioned that if food sovereignty's demands are not met, it constitutes a massive violation of human rights. It was also maintained that, in geopolitical terms, deeper food crisis will undoubtedly engender more collective insecurity [15]. Relatedly, taking statements of former US President Obama at the 2012 G8 Summit, it was indicated that food security is "an economic imperative" since a poorly nourished population is a less economically productive one [12].

Given the above-discussed rationale, the concept of food (in)security needs to be operationalized so that a common understanding could be reached. This is because food (in)security is a dynamic phrase having so many definitions emerging overtime [16-19]. A review of different literature showed that food (in)security has evolved from a focus on availability of food, to access and utilization, and to stability in all dimensions [20]. Notwithstanding all the contentions and varying definitions of food (in) security over time, now scholars seem to agree on the comprehensive definition given on the World Food Summit of 1996. We have adopted the following definition in this paper:
Food security exists when all people at all times have physical or economic access to sufficient, safe and nutritious food to meet their dietary needs and food preferences for an active and healthy life [21].

From this definition one can identify four key dimensions of food security: availability of sufficient food; economic, physical, and social access to the resources needed to acquire food; stability of this availability and access; and utilization that includes nutrition, food safety and quality, clean water, and sanitation [22-25]. Consequently, it can be deducted food insecurity could result if one or more of the key dimensions fail to be fulfilled [12, 26].

So far there have been so many research works conducted in different parts of Ethiopia on food insecurity. However, many of the research works conducted [27-30] used a single indicator (mainly food balance model or calorie availability) to measure the food insecurity situation which could capture only a portion of the whole situation. Such an approach, however, could underestimate the prevalence of food insecurity and its consequences; make the diagnostics difficult; and lead to the design of "one-size-fits-all" interventions [31]. That is why our paper deviates from that traditional way of studying food insecurity by employing multiple indicators so that the situation could be understood comprehensively. In fact, the use of a suite of indicators is a call of the time which is advocated by authoritative organizations such as FAO, IFAD, and WFP and leading scholars such as Carletto et al. [23], Coates [31], to mention few.

Therefore, it is based on the existing high prevalence, recurrence of food insecurity, and the need to study food insecurity in a comprehensive way that this paper was conceived. The paper aims to analyze the food insecurity situation of the rural households in Boset district, which has been a hot spot for food assistance for a long period of time. Besides, identification of determinants of the food insecurity in the study area is the other aim of the study. Thereby, this study could build on similar findings on the topic and would enable to understand food insecurity in its multidimensionality.

\section{Theoretical framework}

There have been so many theories proposed to explain about food insecurity. In fact, the explanatory powers of those theories depend on the time and existing situation of a particular place. Moreover, having recognized the existence of multiple theories of food insecurity, it was contended that among the different theories of famine (food insecurity in this case) no single theory is dominant or capable of excluding the others [32]. Cognizant of this 
fact, we used three of the existing theories to explain the food insecurity situation of the study area.

The first theory considered is the political economy explanation which describes that "the lack of political conditions for an anti-famine contract revolve around anti-democratic tendencies that abrogate any existing democratic rights, thereby hindering timely and effective action to prevent famine, and can therefore be said to involve a famine crime" [32]. This approach attributes famine (food insecurity) occurrence, whatever the economic or natural shocks, to governments' incompetence and lack of commitment at best, or to a deliberate action or inaction at worst [33]. Similarly, Devereux [34] argues that "all famines are explained by a combination of 'technical' and 'political' factors, where political factors include bad government policies, failure of the international community to provide relief, and war." Thus, the political economy explanation suggests that whenever incumbent government authorities and even donors are not delivering what they ought to, food insecurity or famine (in the extreme case) could happen.

Second, the climatic and environmental theory deals with the fact that food insecurity happened with the possible increase of extreme events, in which natural hazards are magnified in intensity and frequency [32]. It was also illustrated that "a combination of arable land lost to population pressure, deforestation and overgrazing, together with the possibility of a long-term decline in rain-fall in dryland farming areas in Africa and Asia, will cause declines in crop production and exacerbate food insecurity" [34]. In a similar vein, it was stated that this approach considers drought (sometimes floods) and recently climate change factors in the explanation of disruption or reduction of food output, which may at the end result in food insecurity [33].

The third theory is concerned with food insecurity as an outcome of vulnerable livelihood. Accordingly, this theory gives explanation in the sense that food insecurity could result when households fail to secure access to the various forms of assets, or when the mediating processes (i.e., institutions, organizations, and social relations at work) are not serving what is expected and/or a combination of these factors when interacting with the existing context (history, trends, and vulnerability/shock) [5].

\section{Methods}

\section{Description of the study area}

Boset district extends between $8^{\circ} 24^{\prime}-8^{\circ} 51^{\prime}$ north latitude and $39^{\circ} 16^{\prime}-39^{\circ} 50^{\prime}$ east longitude. It is located in the northeast part of East Shewa Zone, Oromia National Regional State. It is bordered with Adama district in the west; by Amhara National Regional State in the north; by Fantale district in northeast; and by Arsi Zone in southeast. Data obtained from the population projection by Central Statistical Agency (CSA) [35] indicated that the total population of Boset district for the year 2017 was projected to be 189,795 out of which 42,793 (22.5\%) are urban population and $147,002(77.5 \%)$ are rural population.

Based on a report obtained from the district's Finance and Economic Development Office [36], Boset district is located in the midst of the Rift Valley, which extends from the north to south. The same document revealed that climatically most parts of the district (about 89\%) belong to tropical (kolla) agro-climatic zone and the remaining small section (about 11\%) is subtropical (woina dega) [36]. Similarly, the document [36] showed that the district is characterized by hot and dry weather with an average annual temperature which varies between $25-30{ }^{\circ} \mathrm{C}$ for the tropical (kolla) and $15-20{ }^{\circ} \mathrm{C}$ for the subtropical (woina dega). The rainfall is weakly bimodal with spring (a small rainy season) during the months of April and May, while summer (a long rainy season) during the months of July-September. The average annual rainfall ranges between 700 and $800 \mathrm{~mm}$ with the intensity and variability being high in the district. In terms of drainage system the district falls in the Awash River Basin, with no other major streams and lakes.

\section{Research design and data collection}

This study was conducted in Boset district, East Shewa Zone of Oromia National Regional State. It was undertaken as a cross-sectional survey using mixed methods research approach. The choice of mixed methods was dictated by the research problem under investigation and to benefit from the merits of using this research approach [37-40].

In terms of sources of data, both primary and secondary sources were utilized. The primary data were generated by employing household survey which was administered by 12 Development Agents (DAs ${ }^{1}$ ) who are familiar to the study area and conversant with the local language (Afan Oromo). After pretesting and fully developing the structured questionnaire, it was administered face-to-face. Key informant interviews (KIIs) were also held with heads of offices and focal persons from health, women's and children's affairs, water resources, irrigation, crop production, livestock production, natural resources management, disaster preparedness and prevention, World Vision Ethiopia (Boset Area Development Program), and community elders living in the sample kebeles. ${ }^{2}$

\footnotetext{
${ }^{1}$ Development Agents (DAs) are individuals trained in agriculture colleges for 2 years in areas of crop production, animal health, and natural resources management to promote the agricultural extension program.

${ }^{2}$ A kebele is the lowest community-level administrative organ consisting of a number of villages.
} 
Similarly, focus group discussions (FGDs) with selected 6 men's and 4 women's groups were conducted separately with members comprising 6-10 individuals. The groups were formed on volunteer basis with the help of the DAs working in the respective sample kebeles. The criteria for inclusion in the group discussion were household heads lived in the kebele for more than 5 years and some knowledge on food insecurity issues. Lastly, personal observations coupled with informal discussions were also employed to generate primary qualitative data. In addition, we have utilized current and relevant journal articles which were mainly published within the last 10 years as sources of secondary information.

To have a full picture of the district, a total of 6 kebeles located at different places were selected purposely by the district-level experts after thorough discussion on the topic of the research. Besides, food insecurity status, access to irrigation facilities, and participation in the Productive Safety Net Program (PSNP) were also used as criteria for selecting the kebeles.

List of households living in each of the selected kebeles was taken as a sampling frame, and then respondents selected using systematic random sampling technique proportionate to the size of households living in each kebele. The systematic random sampling technique was employed because it is one of the probability sampling methods and is easy to manipulate during selection of the sample households [41, 42]. Using the formula illustrated by Israel [43], the sample size was calculated, which resulted in a total of 397 participants (48 female- and 349 male-headed households). In the determination of the sample size, a 95\% confidence level and a $p$ value of 0.05 for maximum variability were assumed.

Mathematically, the formula is presented as:

$$
n=\frac{N}{1+N(e)^{2}},
$$

where $n$ stands for the sample size, $N$ signifies the total number of households in all the kebeles, $e$ designates maximum variability which is $5 \%(0.05)$, and 1 stands for the probability of the event occurring.

\section{Data analysis}

\section{Food insecurity analysis}

Based on the nature of the variables measured, to analyze the data collected both descriptive and inferential statistics were employed. Accordingly, to measure the food insecurity status through different indicators, sources of food for households, and mechanisms of filling food gaps we have mainly used percentages, mean, and standard deviation. The final analysis of the quantitative data was performed using STATA, version 12, data management software after the coded responses to the questionnaires were entered into computer. In addition, results of the FGDs, KIIs, and the field observations were transcribed and analyzed according to themes emerged.

Different authors and organizations have suggested the necessity to comprehensively analyze the four dimensions of food (in)security [23, 44] and to use a suite of indicators to capture the complex realities of food insecurity [e.g., 23, 31, 45]. This is because each measure captures and neglects different phenomena intrinsic to the concept of food security, thereby subtly influencing prioritization among food security interventions [46].

Following those suggestions, the indicators we employed include: the identification of Months of Adequate Household Food Provisioning (MAHFP); Household Food Insecurity Access Scale (HFIAS); Household Dietary Diversity Score (HDDS); and assessing the access and use of water supply, sanitation, and hygiene (WASH) facilities.

According to Bilinsky and Swindale [47], when using the MAHFP, although the response options start with the month of January, the respondent is asked to think back over the previous 12 months, starting with the current month. This is done by adjusting the months according to when one conducts the survey so that the current month appears first. Hence, respondents could be asked to identify in which months (during the past 12 months) they did not have access to sufficient food to meet their household needs. The purpose of these questions is to identify the months in which there is limited access to food regardless of the source of the food (i.e., production, purchase, barter or food aid) [47].

Based on information obtained from Namana and Souli [48] and making some modifications households were classified into three categories of food insecurity: least food insecure which includes households that reported being able to satisfy their food requirement for 10-12 months; moderately food insecure which includes households that were able to satisfy their food needs for 7-9 months of the year; and most food insecure which includes households that cannot feed their household members for 6 and more months during the previous year.

The other indicator to food insecurity measurements based on subjective responses is HFIAS [23]. The HFIAS is based on the idea that there is a set of predictable reactions to the experience of food insecurity that can be summarized and quantified, allowing for measurement through household surveys [23, 49].

It was indicted that the HFIAS has a set of nine questions which represent universal aspects of the experience of food insecurity, capturing information on food shortage, food quantity and quality of diet to determine the 
status of a given household's access to food [23]. In addition, households and populations can be classified according to the severity of their food security status along a spectrum, by using data on the severity and frequency of their experiences over the previous 30 days [23].

Based on the description given by Coates et al. [49], the maximum score for a household is 27 (the household response to all nine frequency-of-occurrence questions was "often," coded with response code of 3) and the minimum score is 0 . (The household responded "no" to all occurrence questions, frequency-of-occurrence questions were skipped by the interviewer and subsequently coded as 0 by the data analyst.) The higher the score, the more food insecurity (access) the household experienced. The lower the score, the less food insecurity (access) a household experienced.

The HDDS, on the other hand, is calculated by summing the number of unique food groups consumed during the last $24 \mathrm{~h}$ [23]. The value of this variable will range from 0 to 12, in which lowest HDDS value signifies higher food insecurity status and vice versa. Even though there is no international consensus on which food groups to include in the scores [50], the HDDS denotes 12 food groups in which the following are considered in this study: cereals; root and tubers; vegetables with tubers; vegetables which are leafy; fruits; meat, poultry, offal; eggs; fish; pulses/legumes/nuts; milk and milk products; oil/fats; and sugar/honey.

Based on the findings from a review of different empirical studies made by Ruel [51] and Faber et al. [52] the cutoff point for the HDDS in this study is made that HDDS $\leq 5$ represents low dietary diversity, HDDS 6-7 medium dietary diversity, and HDDS $\geq 8$ high dietary diversity. This categorization could signify most food insecure, medium food insecure, and food secure, respectively.

To obtain a complete picture of the factors that ultimately determine the food insecurity status of a given household, non-food factors were also considered. This is because the various non-food factors contribute to determining the level of the food insecurity outcomes [23]. Accordingly, access to basic services such as clean water and sanitation together with their use was considered in this study.

Hence, based on review of the empirical studies, the MAHFP is used to assess the availability dimension, HFIAS to examine the access dimension, HDDS to measure the quality $[23,51]$, and WASH to assess the utilization dimension. The stability dimension, on the other hand, could be captured by looking into the results of the other three components, as it cuts across all these dimensions $[23,45]$.

\section{Specification of the logit model}

To identify the determinants of household food (in) security a binary logistic regression model was used.
Following the work of Tewodros and Fikadu [29] the functional form of the logistic model is presented as follows:

$$
P_{i}=E\left(Y=1 / X_{i}\right)=\frac{1}{1+e^{-\left(\beta_{o}+\beta_{j} X_{i}\right)}} .
$$

Substituting $\left(\beta_{o}+\beta_{j} X_{i}\right)$ by $Z_{i}$, the equation would become:

$$
P_{i}=\frac{1}{1+e^{-Z_{i}}}=\frac{e^{Z_{i}}}{1+e^{Z_{i}}},
$$

where $P_{i}=E(Y=1)$ is the probability that a household is food secure. $z_{i}$ is a set of explanatory variables of the $i$ th household. $\beta_{o}$ and $\beta_{j}$ are the parameters to be estimated.

If $P_{i}$ is the probability that a household is food secure, as is given in Eq. 2, the probability of food insecurity is then expressed as:

$$
1-P_{i}=\frac{1}{1+e^{z_{i}}} .
$$

From this, the odds ratio in favor of food security thus could be:

$$
\text { The Odds ratio }=\frac{P_{i}}{1-P_{i}}=\frac{e^{Z_{i}} / 1+e^{Z_{i}}}{1 / 1+e^{Z_{i}}}=e^{Z_{i}} .
$$

Since logit model uses logarithmic transformation to assume linearity of the outcome variables on the explanatory variables, the specific logit model to predict the odds of household food security is given in Eq. 5 .

$$
\ln \left[\frac{P_{i}}{1-P_{i}}\right]=Z_{i}=\beta_{0}+\beta_{j} X_{i},
$$

where $\beta_{0}$ is the constant and $\beta_{i}$, where $i=1,2, \ldots j$, are the coefficients of the exogenous variables to be estimated. $X_{i}$ is a vector of explanatory variables.

Description of the variables employed The dependent variable in this model is the result obtained from the HDDS value as measured by counting the food groups that households have consumed during the last $24 \mathrm{~h}$ of the study period. Households with HDDS $\geq 8$ are food secure and represented by 1 , and those with HDDS $<8$ are food insecure and represented by 0 . The independent variables constitute gender, age, educational status, household size, participation in non-farm activities, farmland size, access to irrigable land, total annual income, noticed frequent drought and flood occurrence, access to weather forecast, 
Table 1 Variables hypothesized to affect food security in the study area

\begin{tabular}{|c|c|c|}
\hline Explanatory variables & Description & Expected sign \\
\hline Gender & Dummy takes the value of 1 if male and zero otherwise & + \\
\hline Age & Continuous & $+/-$ \\
\hline Educational status & Dummy takes the value of 1 if formal education and zero otherwise & + \\
\hline Household size & Continuous & $+/-$ \\
\hline Participation in non-farm activities & Dummy takes the value 1 if there is access and zero otherwise & + \\
\hline Farmland size & Continuous & + \\
\hline Access to irrigable land & Dummy takes the value 1 if there is access and zero otherwise & + \\
\hline Total annual income & Continuous & + \\
\hline Noticed frequent drought & Dummy takes the value 1 if they have noticed and zero otherwise & - \\
\hline Noticed frequent flood occurrence & Dummy takes the value 1 if they have noticed and zero otherwise & - \\
\hline Access to weather forecast & Dummy takes the value 1 if there is access and zero otherwise & + \\
\hline Availability of kebele assistance & Dummy takes the value 1 if there is access and zero otherwise & + \\
\hline Access to DA services & Dummy takes the value 1 if there is access and zero otherwise & + \\
\hline Access to health extension services & Dummy takes the value 1 if there is access and zero otherwise & + \\
\hline Access to credit services & Dummy takes the value 1 if there is access and zero otherwise & + \\
\hline Distance from input/output markets & Continuous & - \\
\hline Distance to road transport & Continuous & - \\
\hline Distance to health services & Continuous & - \\
\hline Availability of other (NGO) support organizations & Dummy takes the value 1 if there is access and zero otherwise & + \\
\hline
\end{tabular}

Table 2 Number of months respondents consume their own produce by kebele

\begin{tabular}{|c|c|c|c|c|c|c|c|c|}
\hline \multirow[t]{3}{*}{ Name of kebele } & \multicolumn{6}{|c|}{ Number of months } & \multirow{2}{*}{\multicolumn{2}{|c|}{ Total }} \\
\hline & \multicolumn{2}{|c|}{$3-6$ months } & \multicolumn{2}{|c|}{ 7-9 months } & \multicolumn{2}{|c|}{$10-12$ months } & & \\
\hline & $n$ & $\%$ & $n$ & $\%$ & $\bar{n}$ & $\%$ & $n$ & $\%$ \\
\hline Buta Wagare & 3 & 14.3 & 11 & 52.4 & 7 & 33.3 & 21 & 100.0 \\
\hline D/Wanga & 9 & 30.0 & 13 & 43.3 & 8 & 26.7 & 30 & 100.0 \\
\hline Q/H/Mirqasa & 50 & 31.3 & 100 & 62.5 & 10 & 6.2 & 160 & 100.0 \\
\hline Sara Areda & 5 & 9.6 & 47 & 90.4 & 0 & 0.0 & 52 & 100.0 \\
\hline Sifa Batte & 30 & 27.8 & 75 & 69.4 & 3 & 2.8 & 108 & 100.0 \\
\hline Tiri Birreti & 8 & 30.8 & 13 & 50.0 & 5 & 19.2 & 26 & 100.0 \\
\hline Total & 105 & 26.5 & 259 & 65.2 & 33 & 8.3 & 397 & 100.0 \\
\hline
\end{tabular}

Pearson $\chi^{2}(10)=58.5444, \operatorname{Pr}=0.000$

availability of kebele assistance, access to DA services, access to health extension services, access to credit services, distance from input/output markets, distance to road transport, distance to health services, and availability of other (NGO) support organizations. The variables hypothesized to affect the food security are presented in Table 1 together with their expected sign.

\section{Results and discussion}

\section{Food insecurity as measured by MAHFP}

The availability dimension of the food insecurity of the respondents as measured by the MAHFP indicates that only $8.3 \%$ of them were least food insecure, $65.2 \%$ moderately food insecure, and $26.5 \%$ most food insecure (see Table 2).

Results from Table 2 show across all the kebeles majority of respondents fall in the category of 7-9 months (moderately food insecure). The statistical test conducted also shows there is statistically significant difference $(p<0.001)$ in terms of the number of months respondents encounter food insecurity across the sample kebeles. For example, there was no respondent from Sara Areda kebele who fall in the least food insecure category as compared to $33.3 \%$ of the respondents in Buta Wagare kebele. Here it can be learned that interventions aimed to 
tackle food insecurity in the study area should consider the severity level of the problem.

In line with what was obtained in the survey, key informants and focus group discussants all indicated that food insecurity occurs on seasonal basis. In the words of the focus group discussants "always after Ethiopian Easter is celebrated" food insecurity occurs in most of the kebeles in the study area, which shows a cyclical pattern of inadequate availability and access to food. Focus group discussants in four of the sample kebeles (except Sifa Batte and Q/H/Mirqasa) expressed the months of June to September are those in which households experience the worst food shortage compared to other months. Related to the cyclical pattern of food insecurity, the finding may signify a need for mechanisms to be designed accordingly to avoid the depletion of resources while trying to compensate for the diminishing access to food.

As far as the consequences of the months of inadequate food provisioning is concerned, it was highlighted that seasonality and being food deficit from own production even in normal years can be implicated in making people less food secure [53]. It can also be deducted that the stability component of the respondents' food security could be highly compromised; this is because "stability in the availability of and access to food should be ensured regardless of sudden shocks like climatic crisis or cyclical events which involve seasonal food scarcity" [25].

To fill the gap that is created from consuming own production, opportunities of earning income from nonfarm activities are so important. However, it is only $15.1 \%$ $(n=60)$ of the respondents who reported to engage in different non-farm income-generating activities. Given such limited opportunity for generating income outside their farming, one can imagine what the food insecurity situation could look like, especially for those who are consuming their own produce for only 3-6 months.

Generally, households could have different sources of food for their consumption. And understanding the basic patterns of the sources and how they vary across locations, population groups, and over time will provide a particularly important starting point for understanding the general nature of the food security problem [54]. Accordingly, respondents have identified different sources of food as indicated in Table 3.

Results from Table 3 show all of the respondents obtained food from their own production. This is just because they were engaged in farming activities. Next is obtaining food by purchase (63.2\%), through aid $(40.3 \%)$, and through borrowing (21.9\%). It can be learned that one source of getting food was not adequate to feed the whole family members throughout the year. Again, it can be seen that more than half of the respondents replied to have obtained food from
Table 3 Sources of food for the households (multiple responses)

\begin{tabular}{lrrr}
\hline Sources of getting food & \multicolumn{2}{l}{ Responses } & \multirow{2}{*}{ Percent of cases } \\
\cline { 2 - 3 } & \multicolumn{1}{c}{ Percent } & \\
\hline Get from their own production & 397 & 44.4 & 100.0 \\
Get from purchase & 251 & 28.0 & 63.2 \\
Get their food by borrowing & 87 & 9.7 & 21.9 \\
Get their food through aid & 160 & 17.9 & 40.3 \\
Total & 895 & 100.0 & 225.4 \\
\hline
\end{tabular}

purchase, and that issue of price fluctuation and market in general are important factors that merit special attention when dealing with food insecurity in the study area. This is because "given the heavy dependence of both the rural and urban poor on markets, inflation has potentially devastating effects on the food security of poor households" [55].

Furthermore, it was demonstrated that particularly for the poor, who spend more than $50 \%$ of their income on food consumption, changes in the prices of major staple crops can have a dramatic impact $[56,57]$. Likewise, scholars have again explained that an increase in food prices could have both direct impacts and reductions in real incomes for poor consumers who spend a large share of their income on food that will inhibit their access to available food $[12,58]$.

On the other hand, it can also be seen that getting food through borrowing has the least contribution (Table 3). This is because, according to focus group discussants, the ever increasing poverty of the rural residents and the monetization of everything have eroded the value of supporting each other among the community members.

Since majority of respondents were not found to have consumed only from their own produce throughout the year, and the unavailability of income diversification opportunities could indicate the existence of food gaps. Hence, findings about the mechanisms of filling food gaps from Table 4 show the rural households used different mechanisms of filling food gaps.

The finding shows multiple mechanisms that households used to fill the food gaps they are confronted with. However, non-farm activities, remittance, and borrowing contribute relatively minimum. Besides, most of the mechanisms used by respondents appear to be unreliable.

Looking closely at the mechanisms of filling food gaps some of them need to be treated with special precautions as their end result may not be the one which was intended. For instance, during the study period, it was observed that so many households including those 


\begin{tabular}{|c|c|c|c|}
\hline \multirow[t]{2}{*}{ Food gap filling } & \multicolumn{2}{|c|}{ Responses } & \multirow[t]{2}{*}{ Percent of cases } \\
\hline & $n$ & Percent & \\
\hline Fill food gap through aid & 128 & 19.8 & 33.5 \\
\hline Fill food gap through borrowing & 90 & 14.0 & 23.6 \\
\hline Engage in food-for-work & 158 & 24.5 & 41.4 \\
\hline Engage in non-farm activities & 60 & 9.3 & 15.7 \\
\hline Engage in casual labor & 142 & 22.0 & 37.2 \\
\hline Fill food gap through remittance & 67 & 10.4 & 17.5 \\
\hline Total & 645 & 100.0 & 168.9 \\
\hline
\end{tabular}

considered to be better came to the district agriculture office to complain about their exclusion from benefitting out of the PSNP. Even at times of informal discussions with residents in the district, people told that overcoming the food insecurity problem without the PSNP is unthinkable. Besides, staff members of the food security team in the district mentioned the difficulty in discriminating households who are going to graduate from the program, as there is no one who wants to graduate.

Related to what is physically observed and highlighted by the district staff members, one of the mechanisms that deserve careful handling is food aid. On this issue different scholars advised to handle food aid with caution. For example, it was reported food aid as one of the oldest forms of foreign aid and one of the most controversial [59]. Similarly, Barrett [60] mentioned "while there is effectively universal agreement as to the desirability of the goal of reducing acute and chronic food insecurity, there remains considerable dispute as to how effective food aid is in achieving the goal." It was emphasized the undesirable aspect, "negative dependency," which arises when meeting current needs comes at the cost of reducing recipients' capacity to meet their own basic needs in the future without external assistance [60]. Furthermore, the negative dependency typically arises when individuals, households, or communities alter their behavior in response to the provision of assistance that unwittingly creates disincentives to undertake desirable behavior (e.g., to grow a crop, or to allocate time to work) [60].

In line with the argument made in the preceding paragraph, it was explained that "food aid dependency undermines food security in Ethiopia at every level, from the household to the national government" [61]. This is because the government has little incentive to expend its scarce resources on food security programs as long as the international community remains willing to sink its food surpluses into Ethiopia [61]. Similarly, even very recently it was depicted that "despite the existence of the PSNP, there has not been a reduction in food aid to Ethiopia. In fact, the 2015 appeal issued by the Government of Ethiopia and humanitarian partners is one of the biggest ever at 1.4 bn USD" [62].

Box 1. Reflection of a key informant from World Vision Ethiopia of Boset district. The key informant stated that engaging in daily labor (Merti and Africa Juice companies), charcoal making and firewood selling, petty trading, renting out land with cheap price, diversifying income sources through irrigation, and taking credit from private money lenders are the mechanisms through which the local people fill the food gap created.

As far as food gap filling mechanisms are concerned, it can be deducted that some of the mechanisms, such as food aid, charcoal and firewood selling, and renting out land could result in undesirable results that call for a critical review of the country's strategy. This is because community members (in the case of the study area) and even nations could fall addicted to such quick fixing but downgrading way of solving a problem.

\section{Food insecurity as measured by HFIAS}

Based on the nine generic questions (see Table 5) of the access-related conditions, the finding shows it is only $26.2 \%(n=104)$ who never worried having not enough food, whereas the remaining $73.8 \%(n=293)$ of surveyed households have experienced problems of both economic and physical access to food at varying levels of food insecurity.

Looking at the finding on the basis of the severity level, out of the total score of 2607 , it can be observed that $30.8 \%$ of households encountered access problems "rarely," 41.9\% "sometimes," and 27.3\% "often" during the last 1 month of the study period.

Furthermore, the finding shows the mean score of HFIAS for the respondents is 12.9 with a standard deviation of 4.3, while the minimum and the maximum were 1 and 22, respectively. Based on the categorization made by FAO [63] on a study conducted in Mozambique to determine the cutoff point, a score of $0-11$ was taken as "most food secure"; 12-16 medium food insecure; and a score above 17 most food insecure. Accordingly, it was found in the study that $39.8 \%(n=158)$ were most food secure; $38.5 \%(n=153)$ were medium food insecure; and $21.7 \%$ $(n=86)$ were most food insecure.

Of course, the HFIAS is better interpreted when used to assess Household Food Insecurity Access Prevalence (HFIAP) [10]. Accordingly, the HFIAP indicator categorizes households into four levels of household 
Table 5 Distribution of households by HFIAS condition

\begin{tabular}{|c|c|c|c|c|c|c|c|}
\hline \multirow[t]{3}{*}{ S/no. } & \multirow[t]{3}{*}{ HFIAS conditions } & \multicolumn{6}{|c|}{ Severity status and number of households } \\
\hline & & \multicolumn{2}{|c|}{ Rarely } & \multicolumn{2}{|c|}{ Sometimes } & \multicolumn{2}{|c|}{ Often } \\
\hline & & $n$ & $\%$ & $n$ & $\%$ & $n$ & $\%$ \\
\hline 1 & Worried having not enough food & 152 & 51.88 & 129 & 44.03 & 12 & 4.10 \\
\hline 2 & Not able to eat the food kinds he/she preferred & 55 & 13.90 & 212 & 53.81 & 127 & 32.23 \\
\hline 3 & Able to eat only a limited variety of foods & 6 & 1.52 & 167 & 42.39 & 221 & 56.09 \\
\hline 4 & Able to eat some foods that he/she did not want to eat & 195 & 68.18 & 89 & 31.12 & 2 & 0.70 \\
\hline 5 & Able to eat a smaller meal than he/she felt needed & 47 & 11.93 & 208 & 52.79 & 139 & 35.28 \\
\hline 6 & Able to eat fewer meals/day because there was not enough food & 17 & 4.33 & 165 & 41.98 & 211 & 53.69 \\
\hline 7 & Absolutely no food to eat in the household & 178 & 69.80 & 77 & 30.20 & 0 & 0.00 \\
\hline 8 & Slept at night hungry because there was not enough food & 95 & 73.08 & 35 & 26.92 & 0 & 0.00 \\
\hline \multirow[t]{2}{*}{9} & Went a whole day and night hungry b/c there was not enough food & 58 & 85.29 & 10 & 14.79 & 0 & 0.00 \\
\hline & Total score & 803 & 30.8 & 1092 & 41.9 & 712 & 27.3 \\
\hline
\end{tabular}

Clues to the severity status

(1) Rarely (once or twice in the past 4 weeks)

(2) Sometimes (three to ten times in the past 4 weeks)

(3) Often (more than ten times in the past 4 weeks)

Table 6 Distribution of households by Household Food Insecurity Access Prevalence (HFIAP)

\begin{tabular}{|c|c|c|c|}
\hline \multirow[t]{2}{*}{ Question } & \multicolumn{3}{|c|}{ Frequency } \\
\hline & Rarely & Sometimes & Often \\
\hline 1a & 152 & 129 & 12 \\
\hline $2 \mathrm{a}$ & 55 & 212 & 127 \\
\hline $3 a$ & 6 & 167 & 221 \\
\hline $4 \mathrm{a}$ & 195 & 89 & 2 \\
\hline $5 a$ & 47 & 208 & 139 \\
\hline $6 a$ & 17 & 165 & 211 \\
\hline $7 \mathrm{a}$ & 178 & 77 & 0 \\
\hline $8 \mathrm{a}$ & 95 & 35 & 0 \\
\hline $9 \mathrm{a}$ & 58 & 10 & 0 \\
\hline \multicolumn{4}{|c|}{ Clue to the severity conditions: } \\
\hline & & \multicolumn{2}{|c|}{ Food secure $/$ access $/=9.4 \%$} \\
\hline & & \multicolumn{2}{|c|}{ Mildly food insecure $/$ access $/=27.2 \%$} \\
\hline & & \multicolumn{2}{|c|}{ Moderately food insecure $/$ access $/=33.8 \%$} \\
\hline & & \multicolumn{2}{|c|}{ Severely food insecure $/$ access $/=29.6 \%$} \\
\hline
\end{tabular}

food insecurity (access): food secure, and mild, moderately, and severely food insecure [49]. Thus, households are categorized as increasingly food insecure as they respond affirmatively to more severe conditions and/or experience those conditions more frequently. Results on the HFIAP are presented in Table 6.

Results from Table 6 show there were only few (9.4\%) of the respondents who are food secure; i.e., such households experience none of the food insecure conditions, or just worry, but rarely. To the contrary, the result shows there are 3 times more respondents who were severely food insecure; i.e., households already cut back on meal size or the number of meals often, and/or experience some of the three most severe conditions.

\section{Food insecurity as measured by HDDS}

The results of the finding on the HDDS show respondents were found to have consumed an average of 6 food groups with a standard deviation of 1.53 . Besides, the minimum HDDS value is 3 and the maximum HDDS value is 11 . The detail of the HDDS value across the sample kebeles is presented in Table 7 .

The statistical test made on the results of the overall HDDS shows there is a statistical significant difference across the sample kebeles about the HDDS at $p<0.001$ with a degree of freedom which equals 40 . Hence, based 
Table 7 HDDS for respondents across kebeles

\begin{tabular}{|c|c|c|c|c|c|c|c|c|c|c|c|c|c|c|}
\hline \multirow[t]{3}{*}{ HDDS } & \multicolumn{12}{|c|}{ Names of kebeles } & \multirow{2}{*}{\multicolumn{2}{|c|}{ Total }} \\
\hline & \multicolumn{2}{|c|}{ Buta Wagare } & \multicolumn{2}{|c|}{ D/Wanga } & \multicolumn{2}{|c|}{ Q/H/Mirqasa } & \multicolumn{2}{|c|}{ Sara Areda } & \multicolumn{2}{|c|}{ Sifa Batte } & \multicolumn{2}{|c|}{ Tiri Birreti } & & \\
\hline & $n$ & $\%$ & $n$ & $\%$ & $n$ & $\%$ & $n$ & $\%$ & $n$ & $\%$ & $\bar{n}$ & $\%$ & $n$ & $\%$ \\
\hline 3 & 0 & 0.0 & 1 & 3.3 & 15 & 9.4 & 0 & 0.0 & 3 & 2.8 & 0 & 0.0 & 19 & 4.8 \\
\hline 4 & 0 & 0.0 & 3 & 10.0 & 33 & 20.6 & 2 & 3.8 & 11 & 10.2 & 7 & 27.0 & 56 & 14.1 \\
\hline 5 & 5 & 23.8 & 6 & 20.0 & 55 & 34.4 & 8 & 15.4 & 10 & 9.3 & 5 & 19.2 & 89 & 22.4 \\
\hline 6 & 6 & 28.6 & 5 & 16.7 & 41 & 25.6 & 11 & 21.2 & 26 & 24.1 & 7 & 27.0 & 96 & 24.2 \\
\hline 7 & 6 & 28.6 & 5 & 16.7 & 14 & 8.8 & 14 & 26.9 & 37 & 34.2 & 4 & 15.4 & 80 & 20.1 \\
\hline 8 & 2 & 9.5 & 3 & 10.0 & 1 & 0.6 & 12 & 23.1 & 17 & 15.7 & 1 & 3.8 & 36 & 9.1 \\
\hline 9 & 2 & 9.5 & 6 & 20.0 & 0 & 0.0 & 5 & 9.6 & 4 & 3.7 & 1 & 3.8 & 18 & 4.5 \\
\hline 10 & 0 & 0.0 & 0 & 0.0 & 1 & 0.6 & 0 & 0.0 & 0 & 0.0 & 1 & 3.8 & 2 & 0.5 \\
\hline 11 & 0 & 0.0 & 1 & 3.3 & 0 & 0.0 & 0 & 0.0 & 0 & 0.0 & 0 & 0.0 & 1 & 0.3 \\
\hline Total & 21 & 100.0 & 30 & 100.0 & 160 & 100.0 & 52 & 100.0 & 108 & 100.0 & 26 & 100.0 & 397 & 100.0 \\
\hline
\end{tabular}

Pearson $X^{2}(40)=150.0694, \operatorname{Pr}=0.000$

Table 8 Whether respondents have access to safe drinking water by kebele

\begin{tabular}{|c|c|c|c|c|c|c|}
\hline \multirow[t]{2}{*}{ Name of kebele } & \multicolumn{4}{|c|}{ Access to safe water } & \multicolumn{2}{|c|}{ Total } \\
\hline & No & $\%$ & Yes & $\%$ & $n$ & $\%$ \\
\hline Buta Wagare & 18 & 85.7 & 3 & 14.3 & 21 & 100.0 \\
\hline D/Wanga & 0 & 0.0 & 30 & 100.0 & 30 & 100.0 \\
\hline Q/H/Mirqasa & 121 & 75.6 & 39 & 24.4 & 160 & 100.0 \\
\hline Sara Areda & 42 & 80.8 & 10 & 19.2 & 52 & 100.0 \\
\hline Sifa Batte & 43 & 39.8 & 65 & 60.2 & 108 & 100.0 \\
\hline Tiri Birreti & 2 & 7.7 & 24 & 92.3 & 26 & 100.0 \\
\hline Total & 226 & 56.9 & 171 & 43.1 & 397 & 100.0 \\
\hline
\end{tabular}

Pearson $\chi^{2}(5)=120.2161, \operatorname{Pr}=0.000$

on the categorization discussed earlier about $41.3 \%$ of the respondents were found to consume less dietary diversity, implying they are more food insecure due to lack of the means to acquire and consume a variety of foods. Those who have medium level of food insecurity account for $44.3 \%$, and only $14.4 \%$ of the respondents have HDDS $\geq 8$ that they were food secure and were able to acquire and consume a variety of foods. In fact, it should be noted that the HDDS value could be reduced if sugars and beverages are to be taken out, because they do not add to the nutritional quality of the diet [52].

\section{The nexus between WASH and food insecurity}

When explaining how much water supply and sanitation practices are crucial, it was stated that populations suffering from hunger are often the same as those that lack adequate water and sanitation [64]. On the other hand, it was argued that ensuring poor people's access to safe drinking water and adequate sanitation and encouraging personal, domestic, and community hygiene will improve the quality of life of millions of individuals [65]. Moreover, safe drinking water, sanitation, and hygiene (WASH) contribute significantly to the increased capacity of individuals to absorb and use the nutrients in their food [66].

\section{Access to clean water}

Access to safe drinking water has a direct contribution to the improvement of the food insecurity problem in different ways. Water is a key driver of agricultural production [67], and accessing safe drinking water has the benefits to reduce exposure to a variety of diseases that obstruct the intake and utilization of food and minimizing expenses related to health [68]. In light of these facts respondents were asked about their access to safe drinking water, and the responses are presented in Table 8.

Results from Table 8 show among the sample kebeles respondents of D/Wanga (100.0\%), Tiri Birreti (92.3\%), and Sifa Batte (60.2\%) claimed to have better access to safe drinking water. Their access can be justified (for the first two kebeles) due to their proximity to Wolanchity 
Table 9 Respondents' ownership of latrine by kebele

\begin{tabular}{|c|c|c|c|c|c|c|}
\hline \multirow[t]{2}{*}{ Name of kebele } & \multicolumn{4}{|c|}{ Ownership of latrine } & \multicolumn{2}{|c|}{ Total } \\
\hline & No & $\%$ & Yes & $\%$ & $n$ & $\%$ \\
\hline Buta Wagare & 4 & 19.1 & 17 & 80.9 & 21 & 100.0 \\
\hline D/Wanga & 2 & 6.7 & 28 & 93.3 & 30 & 100.0 \\
\hline Q/H/Mirqasa & 139 & 86.9 & 21 & 13.1 & 160 & 100.0 \\
\hline Sara Areda & 11 & 21.2 & 41 & 78.8 & 52 & 100.0 \\
\hline Sifa Batte & 23 & 21.3 & 85 & 78.7 & 108 & 100.0 \\
\hline Tiri Birreti & 4 & 15.4 & 22 & 84.6 & 26 & 100.0 \\
\hline Total & 183 & 46.1 & 214 & 53.9 & 397 & 100.0 \\
\hline
\end{tabular}

Pearson $x^{2}(5)=181.6547, \operatorname{Pr}=0.000$

town, and for the third kebele its proximity to Bofa (Gode Dhera) town. In the remaining sample kebeles, a significant number of the respondents were not lucky to have access to safe drinking water, thereby forcing to resort to other sources for drinking and other domestic purposes.

Findings of the six sample kebeles show that about $56.9 \%$ of the respondents did not have access to safe drinking water. During the FGDs participants informed that even those who have access did not feel the supply is reliable because the facilities were broken down frequently which forced them either to return back to the unsafe sources, or to spend lots of money to buy water for domestic purposes. When discussing how difficult it was getting safe drinking water, the discussants at $B$ / Wagare kebele pointed out that one jerry can that holds $20 \mathrm{~L}$ will cost them 10 birr after travelling $2 \mathrm{~h}$ on foot. Coupled with the high price, the queue might be so long that sometimes it was in the second day that they could collect the water. A key informant interview made with head of the district's water resources office also showed water shortage was really a serious problem due to deepening of the water table and frequent breakdown of the existing facilities.

As to the implication, it can be said that apart from the direct burden on households' health due to lack of safe drinking water, it has got so many negative implications. For instance, it was mentioned that water availability will be one of the limiting constraints for crop production and food security [69]. In a similar vein, scholars have indicated that farmers' inability to access or control water has an obvious direct impact on potential yields and income, and an indirect impact by reducing potential payoffs from investments in fertilizers, improved seed varieties, and learning technical skills [70].

In a more broader way, it was illustrated that "the lack of adequate water is linked to poverty-households facing water shortages are more likely to be poor or fall into poverty than households not facing such shortages" [71].
Thus, this could imply that households who lack access to water and those who are poor will be more vulnerable to food insecurity. And what is more frustrating is that "... water scarcity will become, more or less, a major threat to food security due to increasing food demand and competition for water resources among sectors" [4].

Among those households who did not get access to safe drinking water an attempt was made to distinguish their sources of drinking water. Accordingly, it was obtained that river/stream (95.6\%) is their chief source of water. In fact, these unsafe sources could have detrimental consequences particularly on the health of individuals and on their food security situation in general. Among the negative effects, it was said lack of access to safe water could result in poor health and affect the physical well-being [68].

As far as the burden of collecting water for different purposes is concerned, FGDs held with both women's and men's groups admitted that collecting water was primarily the responsibility of women, followed by grownup children. This could imply that whenever women are forced to spend more time to haul water, it will reduce their productivity [68] that could end in keeping women in a poverty trap.

\section{Ownership and use of latrines}

Among the WASH components one of them that were treated in this study is ownership and use of latrines. The findings from Table 9 show an interesting result that, except in $\mathrm{Q} / \mathrm{H} /$ Mirqasa kebele, in all the remaining kebeles latrine was owned by the large majority of the respective households.

Despite the ownership of latrines by majority of respondents, however, there was a problem when it comes to the use. FGDs in all the sample kebeles revealed that shortage of water to clean the latrine was bringing bad smell and, as a result, compelled members of households to defecate in unsafe places. A key informant 
Table 10 Respondents' mechanisms of waste disposal

\begin{tabular}{|c|c|c|c|c|c|c|c|c|}
\hline \multirow[t]{3}{*}{ Name of kebele } & \multicolumn{6}{|c|}{ Areas of waste disposal } & \multirow{2}{*}{\multicolumn{2}{|c|}{ Total }} \\
\hline & \multicolumn{2}{|c|}{ Open field } & \multicolumn{2}{|c|}{ In the garden } & \multicolumn{2}{|c|}{ In a waste disposal pit } & & \\
\hline & $n$ & $\%$ & $n$ & $\%$ & $n$ & $\%$ & $n$ & $\%$ \\
\hline B/Wagare & 5 & 23.8 & 3 & 14.3 & 13 & 61.9 & 21 & 100.0 \\
\hline D/Wanga & 5 & 16.7 & 6 & 20.0 & 19 & 63.3 & 30 & 100.0 \\
\hline Q/H/Mirqasa & 54 & 33.7 & 79 & 49.4 & 27 & 16.9 & 160 & 100.0 \\
\hline Sara Areda & 13 & 25.0 & 23 & 44.2 & 16 & 30.8 & 52 & 100.0 \\
\hline Sifa Batte & 38 & 35.2 & 19 & 17.6 & 51 & 47.2 & 108 & 100.0 \\
\hline Tiri Birreti & 4 & 15.4 & 5 & 19.2 & 17 & 65.4 & 26 & 100.0 \\
\hline Total & 119 & 30.0 & 135 & 34.0 & 143 & 36.0 & 397 & 100.0 \\
\hline
\end{tabular}

Pearson $X^{2}(10)=69.9092, \operatorname{Pr}=0.000$

interview held with the head of the district's health office also confirmed the weak usage of latrines due to shortage of water that could be used for cleaning. So the above percentage shows mainly the physical presence of latrines not necessarily their use.

On the other hand, respondents who did not own latrine were inquired to identify the area of defecation they use. Accordingly, about $70.0 \%(n=128)$ expressed to have used bushes and/or forest areas, whereas the remaining $30.0 \%(n=55)$ used open field for defecation. Because of such unsafe practice, the rural households could be denied of the benefits that one can obtain by having sanitation and hygiene facilities and good practices. Sanitation reduces or prevents human fecal pollution of the environment, thereby reducing or eliminating transmission of diseases from that source [65]. It was argued that high-tech solutions are not necessarily the best and some simple latrines can be very effective, while untreated sewage distributes pathogens in the environment and can be the source of disease [65].

\section{Mechanisms of waste disposal}

With recognition of the fact that proper waste disposal could help to avoid disease creating pathogens, respondents were asked to identify the mechanisms they use.

Findings from Table 10 show only $36.0 \%$ of the respondents dispose waste in a waste disposal pit. The remaining $64.0 \%$ of the respondents dispose waste in an unsafe way, either in an open field or in the garden. Such act of unsafe disposal of waste could play a role in transmission of diseases, which signifies the need to be cautious about the surrounding environment where people are residing. This is because "it is insufficient for an individual to receive an adequate quantity of food, if he or she is unable to make use of the food due to illnesses resulting from inadequate sanitation or poor sanitary practices" [23].

\section{Determinants of food (in)security}

As can be observed from Table 11, out of the 19 variables fitted in the binary logistic regression model, 9 significantly affected food insecurity status of the rural households in the study area (Table 11). The discussions made below are based on the findings from Table 11.

Educational status The educational status of the household heads was found to be important in determining their food security situation. With a significance level of less than $5 \%$ household heads with better educational status were more likely to be food secure with a $9.6 \%$ probability. In fact, the inverse relationship of educational status with food insecurity was also found in other empirical studies [27, 29].

Farmland size Having more cultivable land was strongly associated with $11.4 \%$ of being food secure at less than $1 \%$ significance level. This could mean that households with more cultivable land could produce more food, may purchase food for consumption from the income they get from their land, or even may diversify their crop to insure for crop failure. Hence, ways should be sought to lift off the pressure on farmland size.

Access to irrigable land A unit increase in access to irrigable land was associated with $9.3 \%$ probability of being food insecure with a $10 \%$ significance level. This could be due to the meddling of brokers who compel rural households to sell their products with lower prices to those who also cheat them on the scale when measuring the products. Besides, the products which were produced by the farmers require the use of modern inputs which were expensive and not easily available. Thus, the manipulation of the brokers and the cost of modern inputs keep them into a debt spiral that results in food insecurity and even poverty. 
Table 11 Parameter estimates of the binary logit model with their marginal effects

\begin{tabular}{|c|c|c|c|}
\hline Explanatory variables & Coefficients & $p$ value & Marginal effects \\
\hline Gender & 1.146024 & 0.119 & 0.074412 \\
\hline Age & -0.0012422 & 0.955 & -0.0014243 \\
\hline Educational status & 0.931175 & $0.032^{* *}$ & 0.0962907 \\
\hline Household size & -0.0142931 & 0.883 & 0.0016966 \\
\hline Participation in non-farm activities & 0.005792 & 0.990 & -0.001335 \\
\hline Farmland size & 0.9697931 & $0.000^{* * *}$ & 0.1142719 \\
\hline Access to irrigable land & -0.7562149 & $0.099^{*}$ & -0.0926803 \\
\hline Total annual income & 0.0000991 & $0.000^{* * *}$ & 0.0000112 \\
\hline Noticed frequent drought & -0.9546311 & $0.057^{*}$ & -0.1109556 \\
\hline Noticed flood occurrence & -0.2651678 & 0.535 & -0.0221719 \\
\hline Access to weather forecast & 0.8280069 & 0.413 & 0.0247848 \\
\hline Availability of kebele assistance & 0.0351892 & 0.942 & -0.0084927 \\
\hline Access to DA services & 0.7159894 & 0.185 & 0.0503655 \\
\hline Access to health extension services & 0.2784892 & 0.556 & 0.035605 \\
\hline Access to credit services & -0.6171401 & 0.145 & -0.0778475 \\
\hline Distance from input/output markets & -1.676472 & $0.006^{* * *}$ & -0.1401994 \\
\hline Distance to road transport & -0.842344 & $0.066^{*}$ & -0.1036628 \\
\hline Distance from health services & 1.812996 & $0.003^{* * *}$ & 0.1759557 \\
\hline Availability of other support organizations & 0.9402377 & $0.048^{* *}$ & 0.0597707 \\
\hline $\operatorname{LR} x^{2}(19)$ & 103.46 & & \\
\hline Prob $>x^{2}$ & 0.0000 & & \\
\hline Pseudo- $R^{2}$ & 0.3167 & & \\
\hline
\end{tabular}

***,**, ${ }^{*}$ Significant at $1 \%, 5 \%$, and $10 \%$ probability levels, respectively

Total annual income The finding on the total annual income shows the existence of statistically strong evidence $(p<1 \%)$ that an increase in annual income will increase the probability of being food secure, but the corresponding percentage of increment is much lower than $1 \%$. It could be learned that creating more incomegenerating opportunities could be helpful by improving their purchasing power, let farmers use modern inputs that improve their production and productivity, and even make them rent in more farmland that could help them diversify their production activities.

Noticed frequent drought It was obtained from the finding that the more frequent the drought occurs, there is an $11.1 \%$ probability for households to become food insecure at $10 \%$ significance level. This is due to the fact that frequent drought could result in crop failure that impedes the availability of food and reduce income that households could have earned from their production.

Distance to input and output markets Distance to input and outputs markets was found to have a strong negative influence on the food security situation of the households; i.e., a unit increase in distance from input and output markets increases the probability of being food insecure with $14 \%$. This finding is statistically significant at $1 \%$ level. It implies that market centers should be expanded so that distance could be shortened and people will easily get inputs which help them improve their production and productivity and also enable them sell their products to generate more income that will be used for consumption smoothing and diversify their income sources.

Distance to road transport The finding again shows that for a unit increase in the distance from road transport, there is a $10.4 \%$ probability for the households to be less food secure with a statistical significance level of less than $10 \%$. This could be because when distance to road transport increases people may not be encouraged to diversify and produce marketable products.

Distance to health facilities The finding shows an unexpected result that an increase in distance from health facilities is associated with $17.6 \%$ probability of increase in being food security at $\mathrm{p}$ value of less than $1 \%$.

Availability of other supporting organizations It was found that the availability of supporting organizations could improve the food security status of households 
with a probability of $6 \%$. This finding is statistically significant at less than $5 \%$ level. With a great care not to create dependence syndrome, introducing support by partner organizations could assist in smoothing consumption and even may enable households support themselves.

\section{Conclusion}

Food insecurity is more worrisome now than ever before due to the unprecedented variability of the climate and the poverty trap that rural people are in. This paper aimed to examine the food insecurity status and identify their determinants for the rural households in Boset district, East Shewa Zone. The results revealed that households which account $26.5 \%, 21.7 \%$, and $41.3 \%$ are highly food insecure through MAHFP, HFIAS, and HDDS, respectively. In addition, the WASH results show $56.9 \%$, $46.1 \%$, and $64 \%$ of the households did not have access to safe drinking water, did not own latrine, and dispose waste in an unsafe way, respectively. As far as determinants of food security are concerned, it was found that educational status, farmland size, total annual income, distance to health services, and the availability of supporting organizations were positively associated with being food secure. To the contrary, access to irrigable land, occurrence of frequent drought, distance to input and output markets, and distance from road transport were negatively associated with being food secure.

It can be observed that frequent occurrence of drought is found to have statistical significance in making households food insecure. This finding is in line with what the climatic and environmental theories propose in explaining food insecurity. On the other hand, distance from inputs and outputs markets, and from road transport could show the governments' incompetence and lack of commitment in curbing food insecurity as was argued in the political economy explanation. Lastly, the inability to diversify households' income and the frequent drought occurrence could imply the applicability of the theory that contends food insecurity as an outcome of vulnerable livelihood. Our study suggests that due to the seasonal nature of food insecurity, future research may need to be conducted based on longitudinal data so that consistency of findings could be confirmed and interventions could be made efficient. Besides, decision makers in the area should insist in the future about the use of multiple indicators to clearly understand the nature of the prevailing food insecurity and respond accordingly.

\section{Abbreviations}

CSA: Central Statistical Agency; DAs: Development Agents; FAO: Food and Agriculture Organization of the United Nations; FGDs: focus group discussions; HDDS: Household Dietary Diversity Score; HFIAS: Household Food Insecurity
Access Scale; HFIAP: Household Food Insecurity Access Prevalence; IFPRI: International Food Policy Research Institute; KIls: key informant interviews; MAHFP: Months of Adequate Household Food Provisioning; MoARD: Ministry of Agriculture and Rural Development; NGOs: non-governmental organizations; PSNP: Productive Safety Net Program; WASH: water supply, sanitation, and hygiene.

\section{Authors' contributions}

GTM designed the study, collected the data, performed the analysis, and developed the manuscript. DT and NS contributed to the research design and analysis, reviewed and made editorial comments on the draft manuscript. All authors read and approved the final manuscript.

\section{Acknowledgements}

We are grateful for the financial support provided by Addis Ababa University to cover part of the field expenses. We also wish to extend our thanks for all individuals involved in the study from Oromia National Regional State to the kebele levels.

\section{Competing interests}

The authors declare they have no competing interests.

\section{Availability of data and materials}

The authors want to declare that they can submit the data at whatever time based on your request. The datasets used and/or analyzed during the current study will be available from the corresponding author on reasonable request.

\section{Consent for publication}

Not applicable.

\section{Ethical approval and consent to participate}

Ethical approval was not applicable, but consent to participate was granted by each respondent before engaging in the research.

\section{Funding}

Expenses for part of the data collection were covered by Addis Ababa University.

\section{Publisher's Note}

Springer Nature remains neutral with regard to jurisdictional claims in published maps and institutional affiliations.

Received: 17 January 2018 Accepted: 4 September 2018

Published online: 12 September 2018

References

1. Peacock KW. Global issues: food security. New York: Facts on File Inc.; 2012 (An imprint of Infobase Learning).

2. Webb P, Coates J, Frongillo EA, Rogers BL, Swindale A, Bilinsky P. Measuring household food insecurity: why it's so important and yet so difficult to do. J Nutr. 2006;136:1404S-1408S. http://jn.nutrition.org/conte nt/136/5/1404S.full.pdf+html. Accessed 6 June 2017.

3. Godfray HCJ, Beddington JR, Crute IR, Haddad L, Lawrence D, Muir JF, Pretty J, Robinson S, Thomas SM, Toulmin C. Food security: the challenge of feeding 9 billion people. Science. 2010;327:812. https://doi. org/10.1126/science.1185383.

4. Chartres $C$, Sood A. The water for food paradox. Aquat Procedia. 2013;1:3-19. https://doi.org/10.1016/j.aqpro.2013.07.002.

5. Degefa T. Rural livelihoods, poverty and food insecurity in Ethiopia: a case study at Erenssa and Garbi communities in Oromiya Zone, Amhara National Regional State. Ph.D. thesis, Norwegian University of Science and Technology, NTNU, Trondheim; 2005.

6. Messay M. Resettlement and food security nexus in Ethiopia: a case study from Nonno district. Ph.D. thesis, Addis Ababa University. LAP LAMBERT Academic Publishing; 2012. 
7. Meskerem A, Degefa T. Household food security status and its determinants in Girar Jarso Woreda, North Shewa Zone of Oromia region, Ethiopia. J Sustain Dev Afr. 2015;17(7):118-37.

8. Belay K, Dawit A. Agricultural research and extension linkages: challenges and intervention options. Ethiop J Agric Sci. 2017;27(1):55-76.

9. Berhanu A. The food security role of agriculture in Ethiopia. Agricultural and Development Economics Division of FAO. Electron J Agric Dev Econ. 2004;1 (1):138-153. https://ageconsearch.umn.edu/bitst ream/12012/1/01010138.pdf. Accessed 13 June 2018.

10. Guyu FD. Household vulnerability to green famine: component based analysis of indicators in Belo-jiganfoy District (case study area), Benishangul-gumuz region, Ethiopia. Appl Sci Rep. 2015;9(3):139-56. https://doi.org/10.15192/PSCP.ASR.2015.9.3.139156.

11. Oromia Bureau of Agriculture. Oromia region 2007 E.C. (2014/2015 Fiscal year) proposed safety net plan, Finfinne/AA/. Unpublished report; 2014.

12. Jones AD, Ngure FM, Pelto G, Young SL. What are we assessing when we measure food security? A compendium and review of current metrics. Adv Nutr. 2013:4:481-505. https://doi.org/10.3945/an.113.004119.

13. International Food Policy Research Institute (IFPRI). Reaching sustainable food security for all by 2020: getting the priorities and responsibilities right. Washington, DC; 2002. http://www.ifpri.org/publication/ reaching-sustainable-food-security-all-2020-0. Accessed on 13 June 2018.

14. Schanbacher WD. The politics of food: the global conflict between food security and food sovereignty. Santa Barbara: ABC-CLIO, LLC; 2010.

15. Behnnasi M, Yaya S. Food crisis mitigation: the need for an enhanced global food governance. In: Behnassi M, Draggan S, Yaya S, editors. Global food insecurity: rethinking agricultural and rural development paradigm and policy. Berlin: Springer; 2011. p. 93-125. https://doi. org/10.1007/978-94-007-0890-7.

16. Maxwell S. Food security: a post-modern perspective. Food Policy. 1996:21(2):155-70. https://doi.org/10.1016/0306-9192(95)00074-7.

17. Hoddinott J. Choosing outcome indicators of household food security. In: Hoddinot J, editors. Food security in practice: methods for rural development projects. Washington, DC: International Food Policy Research Institute; 2001. pp. 39-45. http://www.ifpri.org/sites/default/files/publi cations/fspractice_01.pdf. Accessed 13 Aug 2014.

18. Carr ER. Postmodern conceptualizations, modernist applications: rethinking the role of society in food security. Food Policy. 2006;31:14-29. https ://doi.org/10.1016/j.foodpol.2005.06.003.

19. Food and Agriculture Organization of the United Nations (FAO). Coping with a changing climate: considerations for adaptation and mitigation in agriculture. Environment and natural resources management series no. 15. Rome, Italy; 2009.

20. Conceicao P, Levine S, Lipton M, Warren-Rodríguez A. Toward a food secure future: ensuring food security for sustainable human development in Sub-Saharan Africa. Food Policy. 2016;60:1-9. https://doi. org/10.1016/j.foodpol.2016.02.003.

21. FAO. Climate change and food security: a framework document. Rome; 2008b. http://www.fao.org/forestry/15538-079b31d45081fe9c3dbc6ff34 de4807e4.pdf. Accessed 2 Dec 2017.

22. Schmidhuber J, Tubiello FN. Global food security under climate change. PNAS. 2007;104(50):19703-8. https://doi.org/10.1073/pnas.0701976104.

23. Carletto C, Zezza A, Banerjee R. Towards better measurement of household food security: harmonizing indicators and the role of household surveys. Glob Food Secur. 2013;2:30-40. https://doi.org/10.1016/j. gfs.2012.11.006

24. Poppy GM, Jepson PC, Pickett JA, Birkett MA. Achieving food and environmental security: new approaches to close the gap. Philos Trans R Soc. 2014;B369:20120272. https://doi.org/10.1098/rstb.2012.0272.

25. FAO. The state of food and agriculture: climate change, agriculture and food security. Rome; 2016. http://www.fao.org/3/a-i6030e.pdf. Accessed 18 Oct 2016

26. Du Toit A, Ziervogel G. Vulnerability and food insecurity: background concepts for informing the development of a national FIVIMS for South Africa; 2004. http://www.agis.agric.za/agisweb/FIVIMS_ZA. Accessed 15 Aug 2014

27. Abebaw S, Ayalneh B. Dimensions of food insecurity and livelihood strategies among rural households in Dire Dawa, Eastern Ethiopia. Trop Sci. 2007;47(2):73-80. https://doi.org/10.1002/ts.199.
28. Guyu FD. Ethno-culture disparity in food insecurity status: the case of Bullen District, Benishangul-Gumuz regional state, Ethiopia. Afr J Food Sci. 2014;8(2):54-63. https://doi.org/10.5897/AJFS2013.1096.

29. Tewodros T, Fikadu T. Determinants of households food security and coping strategies for food shortfall in Mareko District, Guraghe Zone southern Ethiopia. J Food Secur. 2014;2(3):92-9. https://doi.org/10.12691/ jfs-2-3-4.

30. Guyu FD, Muluneh W. Determinants of seasonal food insecurity in the 'green famine' belt of Ethiopia: the case of households in Belo-jiganfoy District, Benishangul-gumuz region. Afr J Food Sci. 2016;10(11):278-91. https://doi.org/10.5897/AJFS2016.1434.

31. Coates J. Build it back better: deconstructing food security for improved measurement and action. Glob Food Secur. 2013;2:188-94. https://doi. org/10.1016/j.gfs.2013.05.002.

32. Wisner B, Blaikie P, Cannon T, Davis I. AT RISK: natural hazards, people's vulnerability and disasters. 2nd ed. London: Routledge; 2004.

33. Ali H. Vulnerability to drought risk and famine: local responses and external interventions among the Afar of Ethiopia, a study on the Aghini pastoral community. Ph.D. dissertation, Department of Social Geography, Faculty of Biology, Chemistry and Earth Sciences University of Bayreuth, Germany; 2008

34. Devereux S. Transfers and safety nets. In: Devereux S, Maxwell S, editors. Food security in Sub-Saharan Africa. Pietermaritzburg: University of Natal Press; 2001. p. 267-93.

35. Central Statistical Agency (CSA). Population projection of Ethiopia for all regions at Wereda level from 2014 to 2017. Federal Demographic Republic of Ethiopia, Addis Ababa; 2013. www.csa.gov.et/.../ehioinfo-inter nal?... population-projection-of-ethiopia-for-all-regions. Accessed 21 Oct 2017.

36. Boset District Finance and Economic Development Office (2012).Physical and socioeconomic profile of Boset district. A document submitted to Oromia Finance and Economic Development Bureau. (Unpublished report).

37. Johnson RB, Onwuegbuzi AJ. Mixed methods research: a research paradigm whose time has come. Educ Res. 2004;33(7):14-26. http://mint| inz.pbworks.com/w/file/fetch/83256376/Johnson\%20Mixed\%20met hods\%202004.pdf. Accessed 11 Feb 2017.

38. Creswell JW. Research design: qualitative, quantitative, and mixed methods approach. 3rd ed. Thousand Oaks: SAGE Publications Inc; 2009.

39. Creswell JW. Educational research: planning, conducting, and evaluating quantitative and qualitative research. 4th ed. Boston: Pearson Education Inc; 2012.

40. Creswell JW, Clark VLP. Designing and conducting mixed methods research. 2nd ed. Thousand Oaks: SAGE Publications Inc; 2011.

41. Babbie E. The basics of social research. 4th ed. Stamford: Thomson Wadsworth; 2008.

42. Bryman A. Social research methods. 4th ed. Oxford: Oxford University Press; 2012.

43. Israel GD. Determining sample size. Institute of Food and Agricultural Sciences (IFAS), University of Florida; 2013. https://www.psycholosphere. com/Determining\%20sample\%20size\%20by\%20Glen\%20lsrael.pdf. Accessed on 2 May 2018.

44. FAO, IFAD, WFP. strengthening the enabling environment for food security and nutrition. Rome: FAO; 2014. p. 2014.

45. Leroy JL, Ruel M, Frongillo EA, Harris J, Ballard TJ. Measuring the food access dimension of food security: a critical review and mapping of indicators. Food Nutr Bull. 2015;36(2):167-95. https://doi.org/10.1177/03795 72115587274.

46. Barrett CB. Measuring food insecurity. Science. 2010;327:825-8. https:// doi.org/10.1126/science.1182768.

47. Bilinsky P, Swindale A. Months of Adequate Household Food Provisioning (MAHFP) for measurement of household food access: Indicator quide (v. 4). Washington, DC: FHI 360/FANTA; 2010. https://www.fantaproje ct.org/sites/default/files/resources/MAHFP_June_2010_ENGLISH_v4.pdf. Accessed 11 Apr 2017.

48. Nanama S, Souli K. Brief: comparison of two methods for measuring household food security and vulnerability — evidence from the Zondoma food security initiative, Burkina Faso. Afr Food Secur Rev. 2007. Washington DC: Africare/Headquarters. http://www.africare.org/at_work/offd/ index.html. Accessed 17 Nov 2017. 
49. Coates J, Swindale A, Bilinsky P. Household food insecurity access scale (HFIAS) for measurement of household food access: Indicator guide (V. 3). Washington, DC: Food and Nutrition Technical Assistance Project, Academy for Educational Development; 2007.

50. FAO. Guidelines for measuring household and individual dietary diversity. Prepared by Gina Kennedy, Terri Ballard and Marie Claude Dop, Nutrition and Consumer Protection Division; 2010. http://www.fao.org/docre p/014/i1983e/i1983e00.pdf. Accessed 13 Jan 2018.

51. Ruel MT. Operationalizing dietary diversity: a review of measurement issues and research priorities. J Nutr. 2003;133:3911S-26S.

52. Faber M, Schwabe C, Drimie S. Dietary diversity in relation to other household food security indicators. Int J Food Saf Nutr Public Health. 2009;2(1):1-15.

53. Ellis, F. Human vulnerability and food insecurity: policy implications. Forum Food Secur South Afr. 2003. https://www.odi.org/sites/odi.org. uk/files/odi-assets/publications-opinion-files/5605.pdf. Accessed 18 Feb 2017.

54. Frank $R$, Nancy $M$, Bruce $C$, Laura B, Eric K. Food security indicators and framework for use in the monitoring and evaluation of food aid programs. Arlington: Food Security and Nutrition Monitoring Project (IMPACT), ISTI, Inc., for the U.S. Agency for International Development; 1999. http://pdf.usaid.gov/pdf_docs/Pnacg170.pdf. Accessed 13 Jan 2018.

55. Ministry of Agriculture and Rural Development (MoARD). Food security program 2010-2014: productive safety net; 2009. http://extwprlegs1.fao. org/docs/pdf/eth144896.pdf. Accessed 18 Apr 2017.

56. Kristkova ZS, Van Dijk M, Van Meijl H. Projections of long-term food security with R\&D driven technical change - a CGE analysis. NJAS Wagening J Life Sci. 2016;77:39-51. https://doi.org/10.1016/j.njas.2016.03.001.

57. Wheeler T, von Braun J. Climate change impacts on global food security. Science. 2013:341:508. https://doi.org/10.1126/science.1239402.

58. Ringler C, Zhu T, Cai X, Koo J, Wang J. Climate change impacts on food security in Sub-Saharan Africa: insights from comprehensive climate change scenarios. IFPRI Discussion Paper 01042; 2010. http://ebrary.ifpri .org/cdm/ref/collection/p15738coll2/id/6983. Accessed 13 Jan 2018.

59. FOA. The state of food and agriculture: food aid for food security? 2006. ftp://ftp.fao.org/docrep/fao/009/a0800e/a0800e.pdf. Accessed 2 Dec 2017

60. Barrett CB. Food aid's intended and unintended consequences. ESA working paper no. 06-05; 2006. http://www.fao.org/3/a-ag301t.pdf. Accessed 2 Dec 2017.

61. Devereux S. Food insecurity in Ethiopia: a discussion paper for DFID; 2000 https://www.ids.ac.uk/files/FoodSecEthiopia4.pdf. Accessed 27 Feb 2016.
62. Sandstrom S, Juhola S. Continue to blame it on the rain? Conceptualization of drought and failure of food systems in the Greater Horn of Africa. Environ Hazards. 2017;16(1):71-91. https://doi.org/10.1080/17477 891.2016.1229656.

63. FAO. Report on use of the household food insecurity access scale and household dietary diversity score in two survey rounds in Manica and Sofala Provinces, Mozambique, 2006-2007; 2008a. http://www.fao. org/fileadmin/user_upload/eufao-fsi4dm/doc-training/moz_diet.pdf. Accessed 13 Jan 2018.

64. Thompson B, Cohen MJ, Meerman J. World food insecurity and malnutrition: scope, trends, causes and consequences. In: Thompson B, Cohen MJ, editors. The impact of climate change and bioenergy on nutrition. Berlin: Springer; 2012. p. 21-41. https://doi.org/10.1007/978-94-007-0110-6.

65. Pruss-Ustun A, Bos R, Gore F, Bartram J. Safer water, better health: costs, benefits and sustainability of interventions to protect and promote health. Geneva: World Health Organization; 2008. http://apps.who.int/ iris/bitstream/10665/43840/1/9789241596435_eng.pdf. Accessed 11 Jan 2017.

66. Rautanen SL, While P. Using every drop-experiences of good local water governance and multiple-use water services for food security in far-western Nepal. Aquat Procedia. 2013;1(2013):120-9. https://doi. org/10.1016/j.aqpro.2013.07.010.

67. Hanjra MA, Qureshi ME. Global water crisis and future food security in an era of climate change. Food Policy. 2010;2010(35):365-77. https://doi. org/10.1016/j.foodpol.2010.05.006.

68. Degefa T, Tesfaye T. Linkages between water supply and sanitation and food security: a case study in four villages of East Hararghe zone, Oromia region; 2008. http://www.rippleethiopia.org/library.php/files/file/20080 908-wp6-water-and-food-security. Accessed 4 Jan 2017.

69. Kang Y, Khan S, Ma X. Climate change impacts on crop yield, crop water productivity and food security - a review. Prog Nat Sci. 2009;19:1665-74. https://doi.org/10.1016/j.pnsc.2009.08.001.

70. Giordano M, de Fraiture C, Weight E, van der Bliek J. (eds) Water for wealth and food security: supporting farmer-driven investments in agricultural water management. Synthesis report of the Ag Water solutions project. Colombo: International Water Management Institute (IWMI); 2012. https ://doi.org/10.5337/2012.207.

71. Faurès J-M, Santini G. (eds) Water and the rural poor: interventions for improving livelihoods in sub-Saharan Africa. Rome: FAO; 2008. http:// www.fao.org/3/a-i0132e.pdf. Accessed 2 Dec 2017.
Ready to submit your research? Choose BMC and benefit from:

- fast, convenient online submission

- thorough peer review by experienced researchers in your field

- rapid publication on acceptance

- support for research data, including large and complex data types

- gold Open Access which fosters wider collaboration and increased citations

- maximum visibility for your research: over $100 \mathrm{M}$ website views per year

At BMC, research is always in progress.

Learn more biomedcentral.com/submissions 